\title{
Hydrothermal Synthesis to Water-stable Luminescent Carbon Dots from Acerola Fruit for Photoluminescent Composites Preparation and its Application as Sensors
}

\author{
Joston Carvalho ${ }^{a}$, Liélia Rodrigues Santos ${ }^{a}$, José Carlos Germino ${ }^{b}$, Ailton José Terezo ${ }^{a}$, \\ Jéferson Aparecido Moreto ${ }^{c *}{ }^{\oplus}$, Fernando Júnior Quites $^{a \dagger}$, Renato Garcia Freitas ${ }^{a}$ \\ ${ }^{a}$ Departamento de Química, Universidade Federal do Mato Grosso, 78060-900, Cuiabá, MT, Brasil \\ ${ }^{b}$ Instituto de Química, Universidade Estadual de Campinas, 13084-971, Campinas, SP, Brasil \\ 'Instituto de Ciências Exatas, Naturais e Educação (ICENE), Universidade Federal do Triangulo \\ Mineiro, 38.064-200, Uberaba, MG, Brasil
}

Received: December 22, 2018; Revised: March 26, 2019; Accepted: April 08, 2019

\begin{abstract}
Carbon dots (C-dots) possess the attractive properties of high stability, low toxicity, good water solubility, simple synthetic routes as well as size and excitation-dependent photoluminescence (PL).The aim of this work was to synthesize photoluminescent $\mathrm{C}$-dots by hydrothermal method using acerola fruit (Malpighiaemarginata) as a row material, since this fruit contains large number of organic molecules. Studies about the optimal synthesis conditions were performed, where these organic molecules were converted into C-dots by hydrothermal carbonization at $180^{\circ} \mathrm{C}$ for $18 \mathrm{~h}$. The C-dots exhibited a green emission light at $459 \mathrm{~nm}$ when excited under UV-light $\left(\lambda_{\mathrm{ex}}=370 \mathrm{~nm}\right)$. These nanomaterials were also successfully used to prepare C-dots/poly (vinyl alcohol) luminescent composites (C-dots/PVA). Both $\mathrm{C}$-dots and C-dots/PVA composite films were investigated by using colorimetric visual sensor for $\mathrm{Fe}^{3+}$ metal ions detection. The results show that the prepared C-dots and C-dots/poly presented strong green emission light. The emission spectra of above materials were quenched in the presence of $\mathrm{Fe}^{3+}$ ions. Thus, highly specific "turn off" fluorescence sensing of $\mathrm{Fe}^{3+}$ was achieved using fluorescent $\mathrm{C}$-dots. Regarding, this work describe that the polymeric films as sensors of metallic ions in aqueous solution appears as a new perspectives to design new composite materials.
\end{abstract}

Keywords: carbon dots, green synthesis, sensors, composite films.

\section{Introduction}

Photoluminescent carbon dots (C-dots), a relatively new member of the carbon nanomaterial family, were firstly produced during purification of single-walled carbon nanotubes by Xu et al in 2004. C-dots are oxygenous carbon nanoparticles with a size of less than $10 \mathrm{~nm}$ with quasi spherical morphology ${ }^{2,3}$ Their excellent photoluminescence properties and tunable fluorescence emission, sensitive not only to the size of the carbon particles, but also to the presence of different analytes (e.g., metal ions, anions) have made this material class widely used as fluorescent labels as well as for chemical sensing applications ${ }^{4}$. Just like heavy-metal-based quantum dots (QDs), they exhibit several promising advantages over organic fluorescence dyes, such as tunable luminescence emission, good solubility in hydrophilic solvents, high stability against photo bleaching and blinking. Nevertheless, the exceptional physicochemical properties such as an excellent water dispersibility (due to the abundant hydrophilic groups on their surface), robust chemical inertness, low toxicity and good biocompatibility, which makes them superior to metal quantum $\operatorname{dots}^{2,3,5}$.

Several raw material including citric acid, coffee grounds, soy milk, fruits and egg have been used in the synthesis of

\footnotetext{
*e-mail: jeferson.moreto.uftm@gmail.com

+ In memorian
}

C-dots. ${ }^{2,4}$ However, it is still desirable to obtained luminescent C-dots by an easy and eco-friendly benign method with lowcost and readily available starting materials, such as using plant as raw materials $\mathrm{s}^{6,7,8,9}$. In this sense, Jiang et al.$^{10}$ produced fluorescent carbon nanoparticles derived from natural materials of mango fruit, by the controlled carbonization method, for bio-imaging probes. Green synthesis of biocompatible carbon dots using aqueous extract of Trapabispinosa peel was also realized by Mewada et al. ${ }^{11}$ Kasibabu et al. ${ }^{12}$ produced, by onestep synthetic, fluorescent carbon dots using a hydrothermal method with Punicagranatum (pomegranate) fruits as precursors and they were used as probes for imaging of bacterial and fungal cells. N. Mehtaa et al. ${ }^{13}$ and Sahu et al. ${ }^{14}$ synthesized C-dots from apple and orange juices, respectively, using hydrothermal treatment for bio-imaging applications.

C-dots are becoming a good alternative for novel fluorescent probes and optical sensors, as a consequence of tunable PL and good biocompatibility ${ }^{2,3,4}$. Recently, C-dots have been demonstrated the use as probes sensitive and selective detection of different ions, such as $\left(\mathrm{Hg}^{2+}\right)^{15,16,17},\left(\mathrm{Cu}^{2+}\right)^{18,19}$, $\left(\mathrm{Fe}^{3+}\right)^{20},\left(\mathrm{Cr}^{6+}\right)^{21},\left(\mathrm{Be}^{2+}\right)^{22}$ ions. For instance, Liu et al. ${ }^{12}$ demonstrated the employed of $\mathrm{C}$-dots as probes for sensitive and selective detection of $\mathrm{Hg}^{2+}$ ions in aqueous solution. The sensing principle was based on fluorescence quenching of C-dots by $\mathrm{Hg}^{2+}$ ions presumably due to facilitating nonradiative electron/hole recombination/annihilation through 
an effective electron or energy transfer process ${ }^{10,11}$. Recently, Shen et al. ${ }^{23}$ reported also a facile synthesis of fluorescence carbon dots from sweet potato for $\mathrm{Fe}^{3+}$ ions sensing and cell imaging. The obtained C-dots with quantum yield of $8.64 \%$ exhibited good dispersibility due to the soluble functional groups on their surfaces.

Inspired by these factors above mentioned, C-dots synthesized from acerola fruit pulp (Malpighiaemarginata) as probe for $\mathrm{Fe}^{3+}$ ions were obtained in this work. To the best of our knowledge, there is no report yet exist to produce C-dots from the acerola fruit, a typical Brazilian fruit. Thus, the development and design of fluorescence sensor for the detection of $\mathrm{Fe}^{3+}$ is becoming an important issue because of the vital roles $\mathrm{Fe}^{3+}$ play in environmental, biological, and chemical systems ${ }^{14}$. The synthesis procedure of $\mathrm{C}$-dots adopted in this study, using acerola fruit as carbon source is presented in Scheme 1, which can be observed in Supporting Information (SI).

The synthesis approach was simple and environmentally friendly. Thus, in first step of this work, it was demonstrated the preparation and characterization of highly fluorescent C-dots water-soluble. Moreover, luminescent composite films based on C-dots and poly (vinyl alcohol) (PVA) were also produced by blended from $\mathrm{C}$-dots and PVA aqueous solution. Both the C-dots solution and the C-dots/PVA films were effectively used as optical and visual sensors for $\mathrm{Fe}^{3+}$ ions detection in aqueous solution.

\section{Experimental}

\subsection{Materials}

All chemicals used were of analytical grade. The PVA was purchased from Sigma Aldrich (USA) with molecular weight $(\mathrm{M} / \mathrm{W})$ of $9000 \mathrm{~g} \mathrm{Mol}^{-1}$, sodium hydroxide $(\mathrm{NaOH})$ Merck (Brazil). The acerola fruit (Malpighiaemarginata) was obtained in Brazilian supermarkets.

\subsection{Synthesis of carbon dots from acerola fruit}

The C-dots were synthesized by simply heating acerola juice in a carbonization method. In a typical procedure, an acerola fruit (c.a. $50 \mathrm{~g}$ ) was cut into small pieces and turned into a paste with $50 \mathrm{~mL}$ of water ${ }^{8,10}$. Then $20 \mathrm{~mL}$ of the juice (pulp-free, solid content $50 \mathrm{mg} \mathrm{mL}^{-1}$ ) was transferred into a $50 \mathrm{~mL}$ Teflon-lined autoclave chamber. After that, the chamber was sealed and put into an oven. Upon completion of hydrothermal reaction in the oven at different times $(12,18,24$ and $36 \mathrm{~h})$ and temperature (100, 130, 160 and $180{ }^{\circ} \mathrm{C}$ ), the reaction product was centrifuged at $8500 \mathrm{rpm}$ for $15 \mathrm{~min}$ to remove the black precipitates after cooling at room temperature.

\subsection{Synthesis of C-dots luminescent film hybrids}

PVA film was synthesized following previously published methods ${ }^{24}$. First, $1.0 \mathrm{~g}$ PVA polymer was dissolved in $25 \mathrm{~mL}$ of water followed by vigorous stirring for $24 \mathrm{~min}$ at $75^{\circ} \mathrm{C}$ to ensure the solubilization of the polymer. After that, C-dots solution colloidal was added into the above solution with stirring. The color of the solution immediately changed pale yellow and the mixture was performed for another $4 \mathrm{~h}$ at room temperature to ensure $\mathrm{C}$-dots dispersion on PVA matrix. Then, the solution blended was placed on oven at $80^{\circ} \mathrm{C}$ for water evaporation and hybrid film formation (PC-dots/PVA). Composite films were named as C-dots/PVA-1 and C-dots/ PVA-2 where the -1 and -2 are related to the $\mathrm{wt} \%$ of C-dots in films as 0.1 and $0.2 \% \mathrm{wt}$, respectively.

\section{$2.4 \mathrm{C}$-dots as $\mathrm{Fe}^{3+}$ ions sensors}

To investigate whether C-dots are stable in presence of some common ions, the effects of kinds of cations, including $\mathrm{Na}^{+}, \mathrm{K}^{+}, \mathrm{Zn}^{2+}, \mathrm{Ca}^{2+}, \mathrm{Hg}^{2+}, \mathrm{Cu}^{2+}, \mathrm{Ni}^{2+}, \mathrm{Pb}^{2+}$ and $\mathrm{Fe}^{3+}$ ions, on the fluorescence intensity of as-prepared $\mathrm{C}$-dots were recorded by fluorescence measurements. Briefly, $10 \mu \mathrm{L}$ of solutions of $\mathrm{NaCl}, \mathrm{KCl}, \mathrm{ZnCl}_{2}, \mathrm{CaCl}_{2}, \mathrm{NiCl}_{2}, \mathrm{PbCl}_{2}, \mathrm{CuCl}_{2}$, $\mathrm{HgCl}_{2}$ and $\mathrm{FeCl}_{3}$ with the concentration of $0.01 \mathrm{~mol} \mathrm{~L}^{-1}$ were added into $1.0 \mathrm{~mL}$ of the as-prepared $\mathrm{C}$-dots. The mixtures were stirred for $3 \mathrm{~min}$ and then the fluorescence spectra of the mixture were investigated under at $370 \mathrm{~nm}$ excitation.

\subsection{Characterization}

UV-visible (Uv-vis) spectra were recorded using a Carry 50 Scan UV-visible spectrometer on 200-800 nm range. Infrared studies (FT-IR) were performed using a Nicolet FT-IR spectrometer. For collecting FTIR spectra and other measures, the samples were lyophilized using a freeze dryer (Terroni model) for 2 days at temperature of $-30{ }^{\circ} \mathrm{C}$ and the IR spectra of C-dots were recorded in $\mathrm{KBr}$ pastilles (number of scans-64).

All steady state fluorescence measurements (excitation and emission spectra) were carried out using Perkin Elmer spectrofluorometer (LS55 model). Excitation and emission slit width were fixed at $2.5 \mathrm{~nm}$. Solid-state fluorescence measurements of C-dots solution and C-dots/PVA composite films were recorded at various excitation wavelength. Time resolved fluorescence measurements were performed using time-correlated single-photon counting (TCSPC). For TCSPC and time-resolved emission spectra (TRES) measurements, excitation wavelength is fixed at $375 \mathrm{~nm}$ and decay profile were collected at $500 \mathrm{~nm}$ (laser pulse width $<370 \mathrm{ps}$ ). UV-Vis and emission spectra were performed using C-dots $10^{-5}$ mol L ${ }^{-1}$ concentration. 


\section{Results and Discussions}

\subsection{Characterization of $C$-dots}

C-dots were synthesized at different times and temperature via the hydrothermal carbonization method, using acerola fruit as carbon source $8,10,25$. In order to obtain C-dots with highest fluorescence intensity, the synthesis conditions such as the hydrothermal temperature and the reaction time were optimized and the results of optical properties (absorption and emission light) are shown in SI as Figures S1, S2, S3 and S4. Based on the optical properties of C-dots obtained from acerola fruit, it can be seen that the absorption intensity continuously increased (Figure S1) with the increasing hydrothermal reaction temperature and the maximum of emission PL intensity was observed to reaction time of $18 \mathrm{~h}$ (Figures S1, S2 and S4). However, the emission spectra contain a maximum in PL relative intensity at $160{ }^{\circ} \mathrm{C}$ for $18 \mathrm{~h}$ of hydrothermal treatment. It is important to note that $\mathrm{C}$-dots prepared under this condition have the highest photoluminescence emission (see also photographic images in the Figure S4 in SI).

Figure 1A displays typical UV-vis absorption and fluorescence spectra of C-dots obtained at $18 \mathrm{~h}$ and $160{ }^{\circ} \mathrm{C}$ conditions of hydrothermal treatment. It is clear that C-dots exhibited broad absorption bands from 200 to $500 \mathrm{~nm}$ with an obvious UV-vis absorption band centered at $282 \mathrm{~nm}$ and shoulder at $343 \mathrm{~nm}$ which are ascribed to $\pi-\pi^{*}$ transitions of the $\mathrm{C}=\mathrm{C}$ bond and $\mathrm{n}-\pi^{*}$ transition of the $\mathrm{C}=\mathrm{O}$ bond, respectively, suggesting that the like-carbon nanoparticle structure was obtained through hydrothermal procedure ${ }^{26}$.

Under the excitation of $\lambda_{\mathrm{ex}}=370 \mathrm{~nm}$, a bright green light centered at $438 \mathrm{~nm}$ can be observed (see inset on Figure 1A) for C-dots synthesized at $18 \mathrm{~h}$ and $160^{\circ} \mathrm{C}$ of hydrothermal treatment. When the excitation wavelength progressively increases from 300 to $410 \mathrm{~nm}$, the maximum emission peak is shifted to longer wavelength from 410 to $504 \mathrm{~nm}$. This unique phenomenon of excitation dependent photoluminescence proved that the reaction products must be photoluminescence $\mathrm{C}$-dots, which was also in agreement with optical properties of those C-dots that were synthesized by other research groups ${ }^{8,10,20,21}$. According to De and $\mathrm{Karak}^{27}$, the intensity of the PL depends on the number of particles excited at a particular wavelength. The highest PL intensity of C-dots was observed at an excitation wavelength of 360 $\mathrm{nm}$ due to the largest number of particles being excited at that wavelength. Another reason for the excitation dependent PL behavior of C-dots is the nature of their surface ${ }^{2-16}$. The presence of various functional groups on the surface of the $\mathrm{C}$-dots may result in a series of emissive traps between $\pi-\pi^{*}$ transitions of C-C. From the digital images presented in inset of Figure 1A, the diluted C-dots solution is tawny under ambient daylight but exhibits strong green photoluminescence emission under UV light (365 nm), which confirmed the good fluorescent property of C-dots produced via green method. The excitation-dependent PL behavior also observed is common for fluorescent carbon materials ${ }^{28}$. Fortunately, excitation-dependent PL behavior can be useful in multi-color imaging applications.

In order to obtain more insights about photophysics dynamics of C-Dots we obtained its fluorescence decays (Figure 2) and time-resolved emission spectra (TRES; Figure 3$)\left(\lambda_{\text {ex }}=375\right.$ $\mathrm{nm})$ at aqueous dilute solution. The decays were recorded at the maximum wavelength (Figure $2 \mathrm{~A} ; \lambda_{\mathrm{em}}=440 \mathrm{~nm}$ ) and at the edge (Figure $1 \mathrm{~B} ; \lambda_{\mathrm{em}}=500 \mathrm{~nm}$ ) of the emission spectrum (Figure 1). As expected, C-Dots exhibited a multi exponential behavior at its fluorescence decays at the two emissions with tri components: $\lambda_{\mathrm{em}}=440 \mathrm{~nm} \tau_{1}=1.050 \pm 0.044 \mathrm{~ns}(28 \%)$, $\tau_{2}=3.034 \pm 0.010 \mathrm{~ns}(51 \%)$ and $\tau_{3}=9.845 \pm 0.004 \mathrm{~ns}$ $(21 \%)$; and $\lambda_{\mathrm{em}}=500 \mathrm{~nm} \tau_{1}=0.773 \pm 0.074 \mathrm{~ns}(20 \%)$, $\tau_{2}=3.015 \pm 0.009 \mathrm{~ns}(46 \%)$ and $\tau_{3}=9.322 \pm 0.002 \mathrm{~ns}$ (34\%). This phenomenon should be directly linked to a high dispersion of sizes and shapes of acerola C-Dots due its synthesis procedure. However, since the frequencies suffered short changes of its values, we can conclude that is an excellent concentration to work with these C-Dots
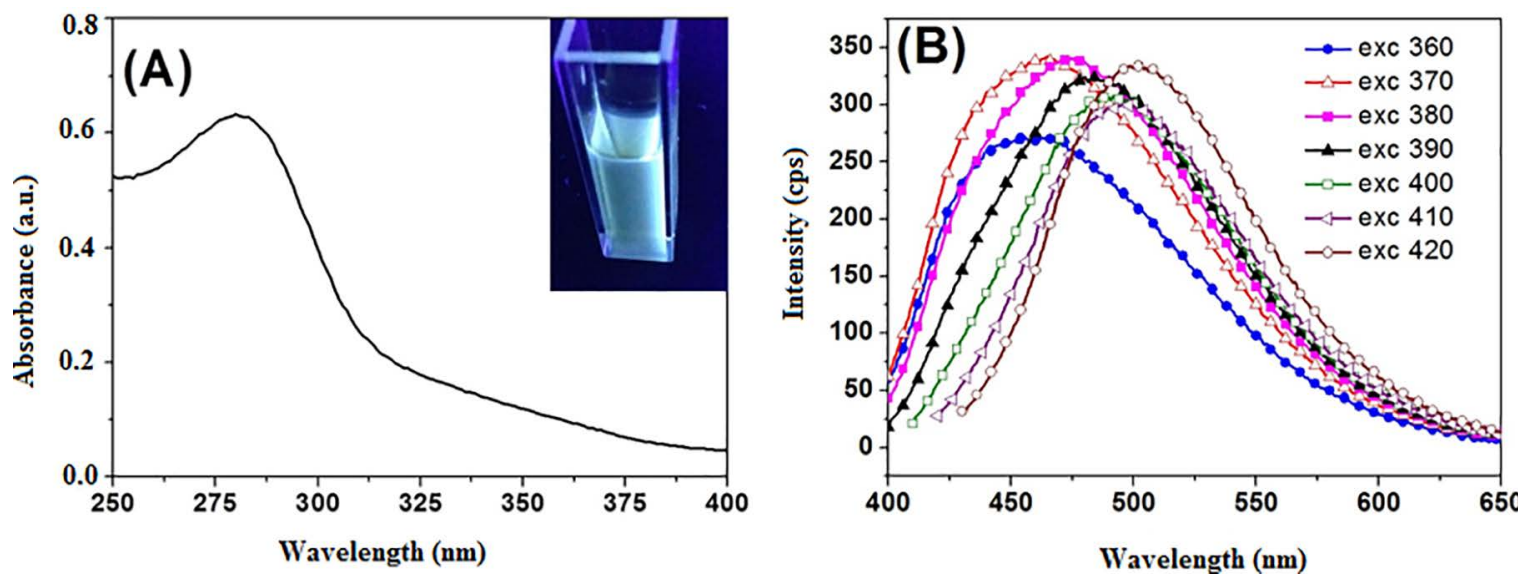

Figure 1. (A) UV-vis spectrum and (B) room temperature PL spectra at different excitation wavelengths of C-dots solution obtained at different time and temperature $\left(18 \mathrm{~h}\right.$ and $\left.160{ }^{\circ} \mathrm{C}\right)$ of hydrothermal treatment. 

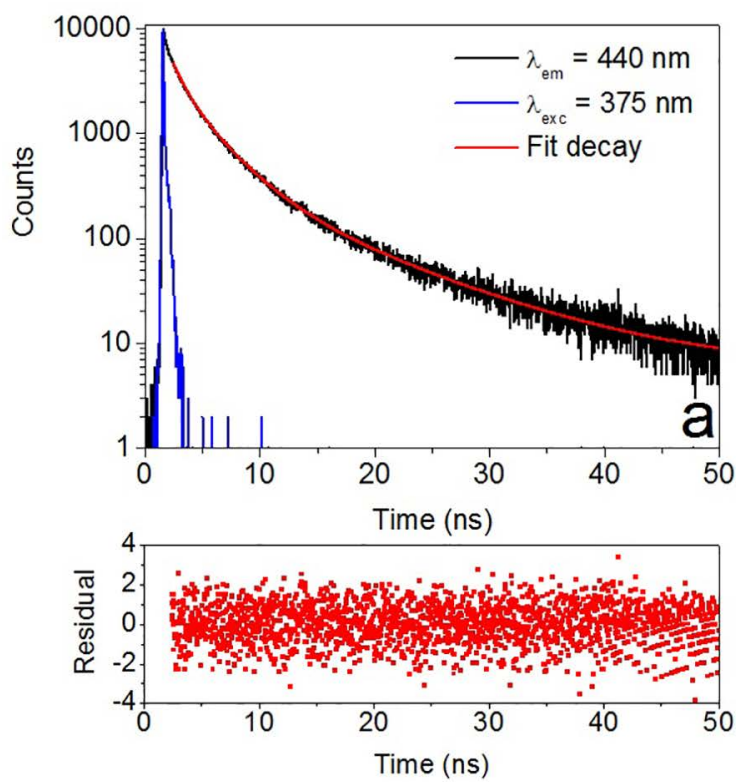

Figure 2. Fluorescence decays of C-Dots diluted aqueous solution $\left.\left(\lambda_{\mathrm{exc}}=375 \mathrm{~nm}\right): \mathrm{a}\right) \lambda_{\mathrm{em}}=440 \mathrm{~nm}$; and b) $\lambda_{\mathrm{em}}=500 \mathrm{~nm}$.

without presence of aggregates. The short lifetime of the $\mathrm{C}$-dots is an indicative of the radiative recombination of the excitons, giving rise to fluorescence ${ }^{25}$. As we know, diverse chromophores or energy levels present in the samples are responsible for their multiple lifetimes ${ }^{29}$.

Thereby, the C-Dots normalized TRES at aqueous solution ( $\lambda_{\mathrm{ex}}=375 \mathrm{~nm}$; Figure 3 ) were done between 0-18.838 ns delays. A red-shift of the emissions spectra was observed along the time evolution of the experiment: at $\mathrm{t}=0 \mathrm{~ns}, \lambda_{\text {em(i) }}=435 \mathrm{~nm}$ (red curves insert Figure 3 ); and $\mathrm{t}_{\mathrm{f}}$, $\lambda_{\mathrm{em}(\mathrm{f})}=455 \mathrm{~nm}$ (blue curves insert Figure 3). This behavior proves the possibility of the presence of different types of shapes and sizes of C-Dots.

The stability of the fluorescent C-dots at different $\mathrm{pH}$ values was evaluated in order to verify the responses to changes in $\mathrm{pH}$ were also evaluated. A series of fluorescent C-dots solutions (prepared at $18 \mathrm{~h}$ and $160{ }^{\circ} \mathrm{C}$ ) with $\mathrm{pH}$ ranging systematically from 1 to 13.0 were prepared, and the fluorescence intensity of C-dots at different $\mathrm{pH}$ values was monitored with a spectrofluorometer. Significant changes in emission intensity were observed as the $\mathrm{pH}$ was varied, as depicted in Figure 4. It is obvious that the emission intensity reaches the maximum value at $\mathrm{pH}=3$, but it decreases dramatically from $\mathrm{pH}=3$ to $\mathrm{pH}=10$ and changes a little at higher $\mathrm{pH}$ values (10-13). These results demonstrated that under low $\mathrm{pH}$ values, the C-dots, probably, were dissolved as isolated species in the aqueous solution; in contrary, the agglomeration of nanoparticles appeared with increasing the $\mathrm{pH}$ value because of non-covalent molecular interactions, such as hydrogen bonds between the carboxyl groups ${ }^{18,30}$. Hence, $\mathrm{pH}$-induced aggregations of the as-prepared $\mathrm{C}$-dots result in an obvious fluorescence quenching at high $\mathrm{pH}$ values ${ }^{18}$.
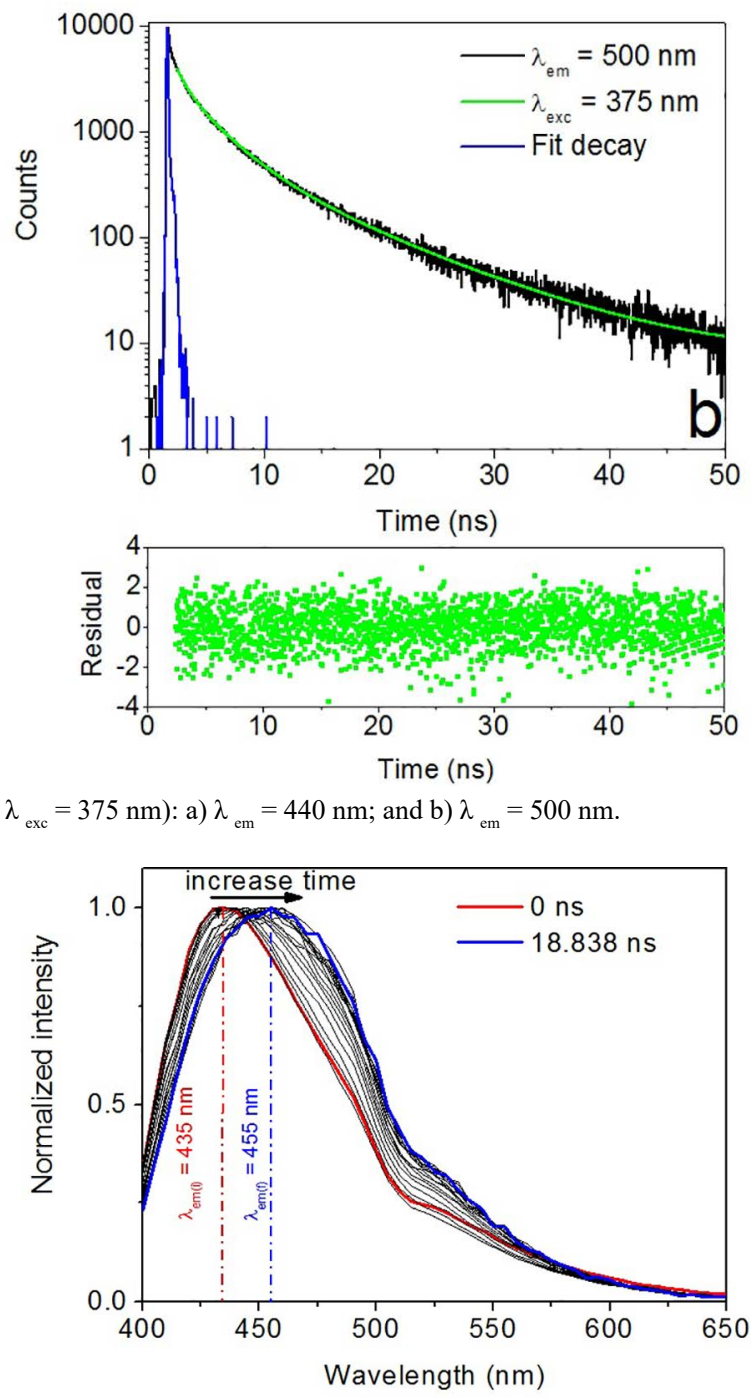

Figure 3. Normalized time-resolved emission spectra (TRES) of C-Dots in diluted aqueous solution ( $\lambda_{\text {exc }}=375 \mathrm{~nm}$; delay 0-18.838 ns).

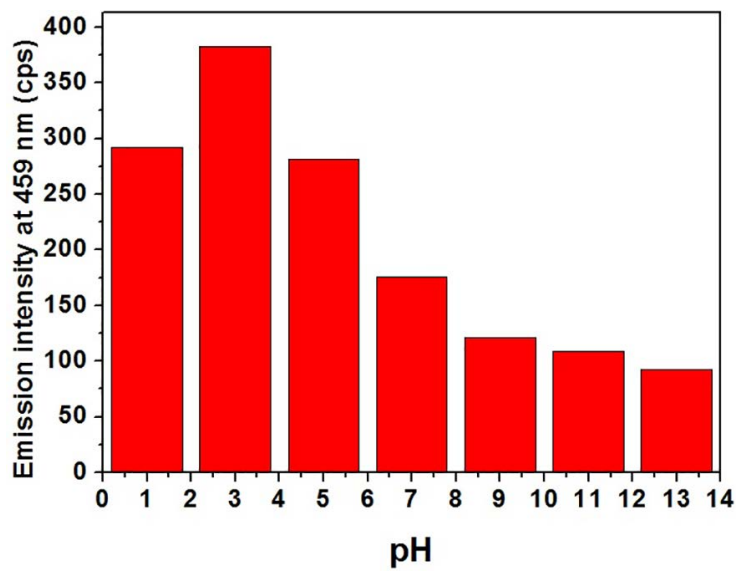

Figure 4. pH stability of C-dots colloidal solution.

FT-IR measures were also used to study structure of C-dots. As can be seen in Figure 5, C-dots showed a main 
absorption band of $\mathrm{O}-\mathrm{H}$ at $3430 \mathrm{~cm}^{-1}, \mathrm{C}-\mathrm{H}$ at 2970 and $2850 \mathrm{~cm}^{-1}$, stretching vibration of $\mathrm{C}=\mathrm{O}$ at $1570 \mathrm{~cm}^{-1}$, the typical band of the amine C-N bond is at $1430 \mathrm{~cm}^{-1}$. The stretching vibration bands of C-O at 1091 and $787 \mathrm{~cm}^{-1}$ indicated the presence of carboxylic acid and other oxygencontaining functional groups. These results showed that $\mathrm{C}$-dots are rich in carboxylic groups, which make it as high water solubility ${ }^{14}$.

\subsection{Detection of $\mathrm{Fe}^{3+}$ ions}

The as-prepared C-dots may be used to fabricate a highly sensitive and selective FL sensor for metallic ions without further modification. As demonstrated in Figure 1A and in Figures S2 and S4 (see SI), the solution of as-prepared C-dots exhibited abroad emission band centered at $496 \mathrm{~nm}$ when excited at $370 \mathrm{~nm}$. The bright green fluorescence of

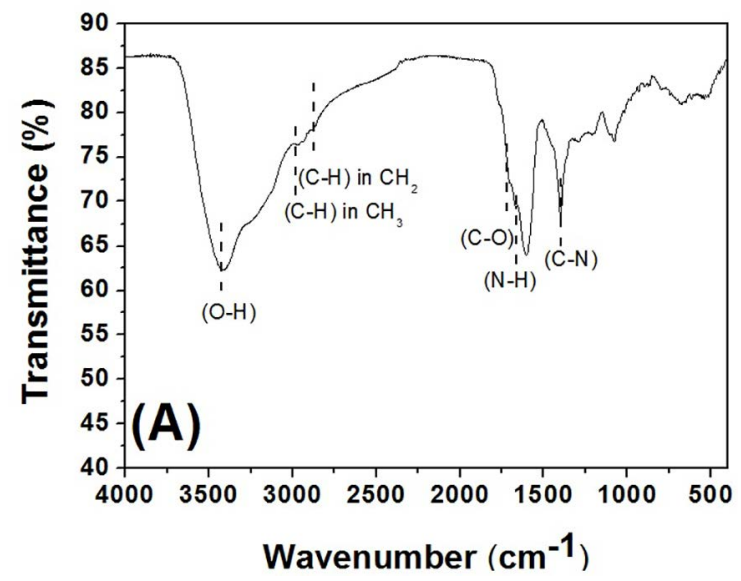

Figure 5. FTIR spectrum of C-dots prepared at $18 \mathrm{~h}$ and $160{ }^{\circ} \mathrm{C}$ treatment hydrothermal conditions. the C-dots under UV light is strong enough to be seen by the naked eye, but when iron ions was added, the fluorescent color was noticeably decreases. Moreover, the colors of the solution changed from bright green to light green as iron ions concentration was increased (see Figure 6D). This indicates that the synthesized C-dots may be used as highly selectivity and sensitivity analysis for $\mathrm{Fe}^{3+}$ ions detection as shown in Figures 6A and 6B.

As demonstrated in Figure 6A, in the presence of different $\mathrm{Fe}^{3+}$ ions concentrations, the PL intensity of C-dots was quenched effectively through the efficient charge and energy transfer process ${ }^{12,19}$. In addition to PL change, the variation in the UV-vis absorption spectrum of C-dots (Figure 6D and the digital image of C-dots solution on $\mathrm{Fe}^{3+}$ ions presence on inset of Figure $6 \mathrm{E}$ ) demonstrated that $\mathrm{Fe}^{3+}$ ions can influence the surface states of C-dots ${ }^{13,16}$. The decreases of the fluorescence intensity exhibited a linear response with the increasing $\mathrm{Fe}^{3+}$ ions concentration in the range of 0.001-0.012 $\mathrm{mol} \mathrm{L}^{-1}$ (Figure 6B) revealing that sensing is sensitive to $\mathrm{Fe}^{3+}$ ions. The relative intensity $\left(\mathrm{I} / \mathrm{I}_{0}\right)$ against increasing iron ions concentration exhibited excellent linearity with a correlation coefficient of $R^{2}=0.9925$, as shown in Figure 6D. It fits the linear Stern-Volmer equation, illustrating a photophysical process by a single reaction (static quenching) ${ }^{12,31}$. According to the Li et al. ${ }^{16}$, the fluorescence of the $\mathrm{C}$-dots could be quenched by $\mathrm{Fe}^{3+}$ ions due to the special coordination interaction between $\mathrm{Fe}^{3+}$ and the $\mathrm{C}$-dots. Fluorescence quenching may contribute to non-radiative electron transfer that involves partial transfer for an electron in the excited state to the d orbital of $\mathrm{Fe}^{3+}$. In addition, we also investigated the fluorescence quenching effect of other metal ions $\left(\mathrm{Na}^{+}, \mathrm{K}^{+}, \mathrm{Zn}^{2+}, \mathrm{Ag}^{+}, \mathrm{Pb}^{2+}, \mathrm{Ni}^{2+}\right.$, $\mathrm{Hg}^{2+}$ and $\mathrm{Cu}^{2+}$ ) on C-dots (Figure 7). Different metal ions
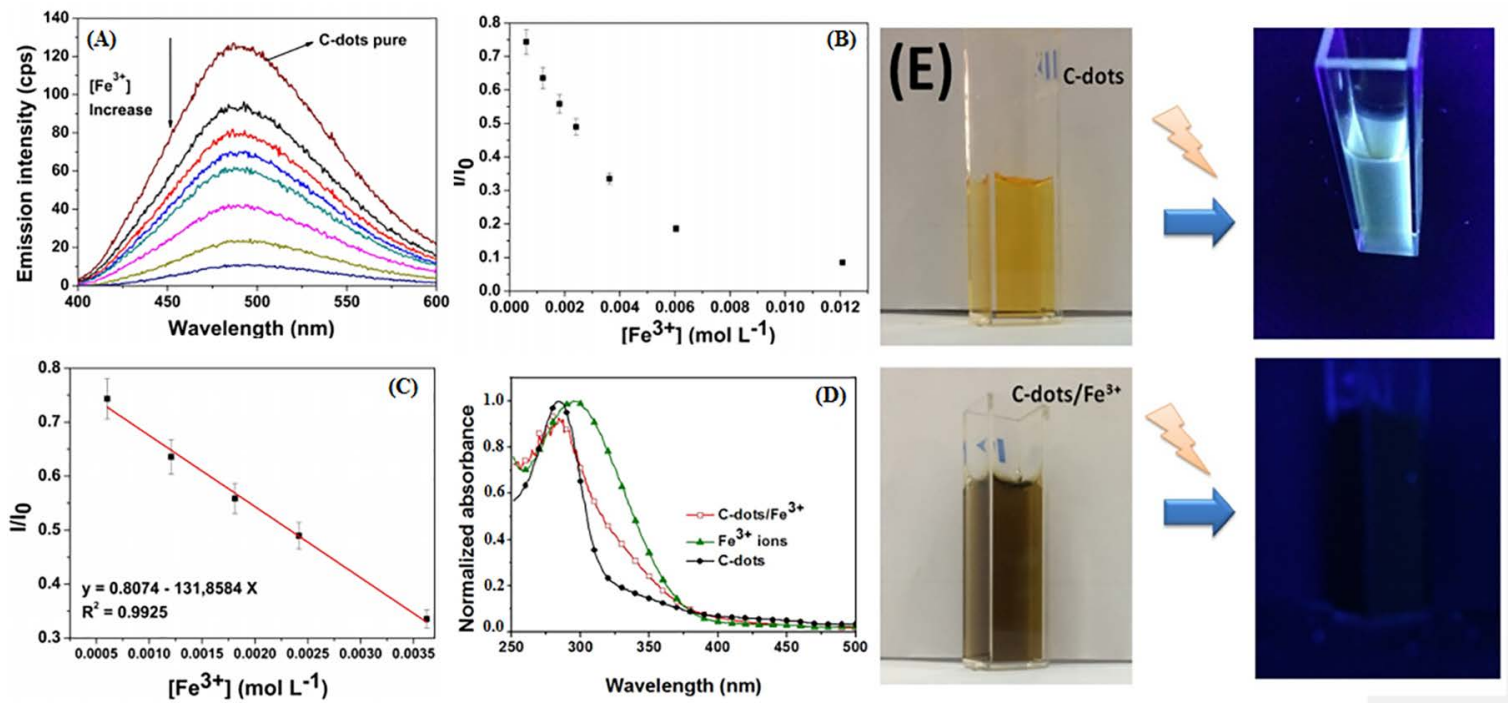

Figure 6. (A) Typical PL emission spectra of as-prepared C-dots in the presence of increasing Fe $\mathrm{F}^{3+}$ concentrations $(0-40 \mathrm{mM})$. (B) The relationship between $\mathrm{I} / \mathrm{I}_{0}$ and $\mathrm{Fe}^{3+}$ concentrations. I and $\mathrm{I}_{0}$ are the PL intensities of C-dots excited at $360 \mathrm{~nm}$ in the presence and absence of $\mathrm{Fe}^{3+}$ ions, respectively.(C) The dependence of $\left(\mathrm{I} / \mathrm{I}_{0}\right)$ on concentrations of $\mathrm{Fe}^{3+}$.(D) $\mathrm{UV}$-vis spectra of $\mathrm{C}$-dots in the absence and the presence of $\mathrm{Fe}^{3+}$ ions. (E) Photographic image of $\mathrm{C}$-dots in the presence and absence of $\mathrm{Fe}^{3+}$ ions (under visible and $\mathrm{UV}$ lights). 
with a concentration of $0.002 \mathrm{~mol} \mathrm{~L}^{-1}$ were added into C-dots solution ( $2 \mathrm{~mL}$ ). Different quenching degrees were also observed. Though $\mathrm{Ag}^{+}$ions also presented a relatively strong quenching effect, the most promising results were demonstrated by $\mathrm{Fe}^{3+}$ ions (Figure 7).

\subsection{C-dots/PVA film preparation}

C-dots derived from acerola fruit was used as probes and they were well dispersed on PVA polymer for luminescent films preparation. As shown in Figure S5 (see SI) C-dots/ PVA composite obtained from C-dots and PVA blended solutions displayed transparent films and when illumined by UV lamp a green emission can be detected by eye naked due the $\mathrm{C}$-dots presence on PVA polymer matrix.

The UV-vis spectrum (Figure 8A) of this film presented absorption band at 282 and 341 associated to the $\pi \rightarrow \pi^{*}$ and $\mathrm{n} \rightarrow \pi^{*} \mathrm{C}$-dots transitions, respectively.

To further support about the optical properties of C-dots dispersed on PVA films, photoluminescence measures were also evaluated. Analogous to those previously reported ${ }^{2-20}$, the

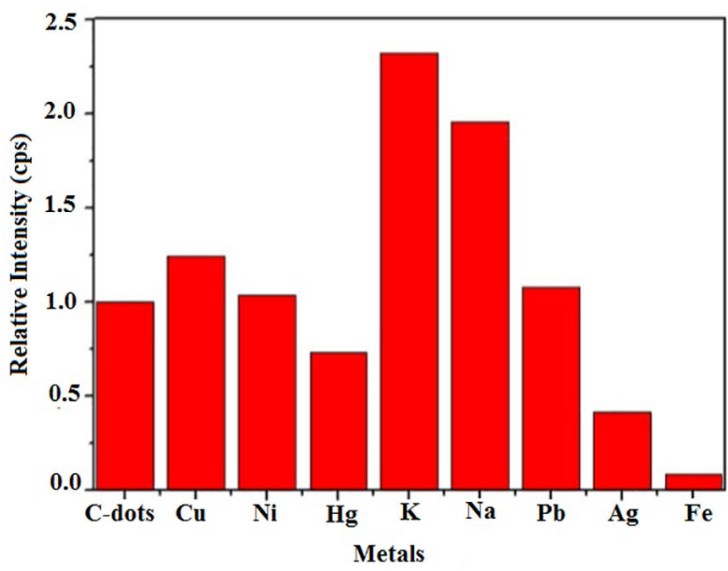

Figure 7. Performance of optical sensors based on as-prepared C-dots: comparison of fluorescence intensities in the absence and presence of different metal ions.

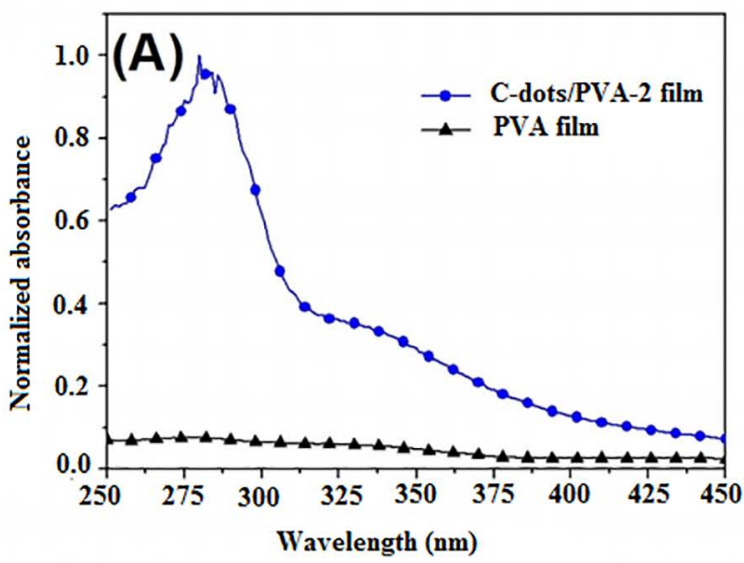

PL emission spectra for the C-dots/PVA-1 film (Figure 8B) exhibited a typical excitation-dependent feature, where the emission peak red shifts to longer wavelengths with the increase in the excitation wavelength. Moreover, the maximum emission intensity of C-dots/PVA film was observed at $459 \mathrm{~nm}$ when excitation wavelength was $360 \mathrm{~nm}$ maybe due to the nature of $\mathrm{C}$-dots surface and the maximum number of particles being excited at $360 \mathrm{~nm}$.

To gain more insights about the optical properties of C-dots/PVA composite as $\mathrm{Fe}^{3+}$ sensing, the C-dots/PVA film was immersed on $\mathrm{Fe}^{3+}$ aqueous solution and the results are shown in Figure S6 (see SI). After direct contact between $\mathrm{Fe}^{3+}$ solution and C-dots/PVA-1 film, under visible light Figure S5 (see SI), the polymer film changed its coloration as already observed for the studies taken in aqueous solution (see Figure 6).This is a strong evidence of the complex formation between $\mathrm{Fe}^{3+}$ ions and $\mathrm{C}$-dots in $\mathrm{C}$-dots/PVA composite film. Furthermore, under UV light, the C-dots/ PVA-2 film has its emission quenching due the $\mathrm{Fe}^{3+}$ and C-dots interactions Figure S6 (see SI).

These results clearly suggest that the synthesized C-dots were well dispersed on PVA polymer matrix and that the functional hydroxyl groups of PVA can stabilized/solubilized the C-dots fluorophores, which allows us to use them as ecofriendly probes in sensing investigations of metallic ions.

\section{Conclusions}

In summary, we synthesized water-soluble fluorescent C-dots by the hydrothermal method using a common carbon resource (acerola fruit). The nanoparticles were stable under ambient conditions, and they can exhibit excellent photoluminescence emission. The C-dots were successfully dispersed on PVA polymer matrix for composite luminescent film preparation. Both $\mathrm{C}$-dots and $\mathrm{C}$-dots/PVA films showedhighsensitivityforFe ${ }^{3+}$ relative to other metal ions such as $\mathrm{Na}^{+}, \mathrm{Ni}^{2+}, \mathrm{Ag}^{+}, \mathrm{Pb}^{2+}, \mathrm{Hg}^{2+}, \mathrm{K}^{+}, \mathrm{Zn}^{2+}$ and $\mathrm{Cu}^{2+}$ ions, by reducing the fluorescence emission at $456 \mathrm{~nm}$. As the

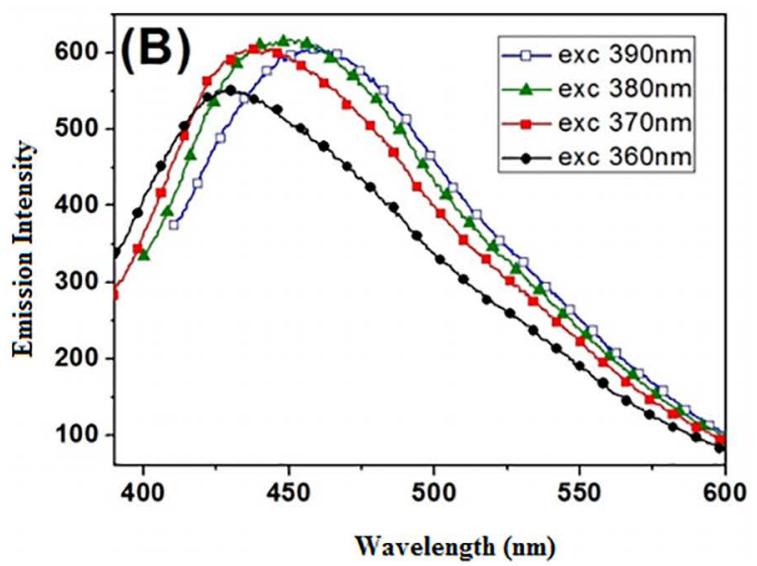

Figure 8. (A) UV-vis spectrum and (B) room temperature PL spectra at different excitation wavelengths of composite film based on C-dots with PVA polymer (C-dots/PVA-2). For comparison UV-vis spectrum of PVA polymer also is presented. 
photoluminescence intensity of C-dots prepared in this study can be greatly affected by $\mathrm{Fe}^{3+}$ ions in water, they might be a good candidate for the detection of $\mathrm{Fe}^{3+}$ ions. Moreover, both the precursors and the prepared $\mathrm{C}$-dots are environmentally friendly and the preparation method is simple showing that the $\mathrm{C}$-dots and the C-dots/PVA composites are promising as fluorescent sensors to detect metallic ions.

\section{Acknowledgments}

We lost a brilliant scientist and an extraordinary professor (Fernando Júnior Quites $^{\dagger}$ ) in the Chemistry Department of Federal University of Mato Grosso (UFMT). We missed a very good friend and excellent colleague, however, your spirit and youth is forever with us. He worked so hard, now rest in peace. He will always be in our memory.

\section{References}

1. Xu X, Ray R, Gu Y, Ploehn HJ, Gearheart L, Raker K, et al. Electrophoretic Analysis and Purification of Fluorescent SingleWalled Carbon Nanotube Fragments. Journal of the American Chemical Society. 2004;126(40):12736-12737.

2. Baker SN, Baker GA. Luminescent Carbon Nanodots: Emergent Nanolights. Angewandte Chemie - International Edition. 2010;49(38):6726-6744.

3. Kumar A, Chowdhuri AR, Laha D, Mahto TK, Karmakar P, Sahu SK. Green synthesis of carbon dots from Ocimum sanctum for effective fluorescent sensing of $\mathrm{Pb}^{2+}$ ions and live cell imaging. Sensors and Actuators B: Chemical. 2017;242:679-686.

4. Lim SY, Shem W, Gao Z. Carbon quantum dots and their applications. Chemical Society Reviews. 2015;44(1):362-381.

5. Li H, Kang Z, Liu Y, Lee ST. Carbon nanodots: synthesis, properties and applications. Journal of Materials Chemistry. 2012;22(46):24230-24253.

6. Mehta VN, Jha S, Singhal RK, Kailasa SK. Preparation of multicolor emitting carbon dots for HeLa cell imaging. New Journal of Chemistry. 2014;38(12):6152-6160.

7. Bhamore JR, Jha S, Singhal RK, Park TJ, Kailasa SK. Facile green synthesis of carbon dots from Pyrus pyrifolia fruit for assaying of $\mathrm{Al}^{3+}$ ion via chelation enhanced fluorescence mechanism. Journal of Molecular Liquids. 2018;264:9-16.

8. Mehta VN, Jha S, Kailasa SK. One-pot green synthesis of carbon dots by using Saccharum officinarum juice for fluorescent imaging of bacteria (Escherichia coli) and yeast (Saccharomyces cerevisiae) cells. Materials Science and Engineering: $C$. 2014;38:20-27.

9. Kailasa SK, Ha S, Baek SH, Phan LMT, Kim S, Kwak K, et al. Tuning of carbon dots emission color for sensing of $\mathrm{Fe}^{3+}$ ion and bioimaging applications. Materials Science and Engineering: C. 2019;98:834-842.

10. Jeong CJ, Roy AK, Kim SH, Lee JE, Jeong JH, In I, et al. Fluorescent carbon nanoparticles derived from natural materials of mango fruit for bio-imaging probes. Nanoscale. 2014;6(24):15196-15202.
11. Mewada A, Pandey S, Shinde S, Mishra N, Oza G, Thakur $\mathrm{M}$, et al. Green synthesis of biocompatible carbon dots using aqueous extract of Trapa bispinosa peel. Materials Science and Engineering: C. 2013;33(5):2914-2917.

12. Kasibabu BSB, D'souza SL, Jha S, Singhal RK, Basu H, Kailasa SK. One-step synthesis of fluorescent carbon dots for imaging bacterial and fungal cells. Analytical Methods. 2015;7(6):23732378.

13. Mehta VN, Jha S, Basu H, Singhal RK, Kailasa SK. One-step hydrothermal approach to fabricate carbon dots from apple juice for imaging of mycobacterium and fungal cells. Sensors and Actuators B: Chemical. 2015;213:434-443.

14. Sahu S, Behera B, Maiti TK, Mohapatra S. Simple one-step synthesis of highly luminescent carbon dots from orange juice: application as excellent bio-imaging agents. Chemical Communications. 2012;48(70):8835-8837.

15. Lu WB, Qin XY, Liu S, Chang GH, Zhang YW, Luo YL, et al. Economical, Green Synthesis of Fluorescent Carbon Nanoparticles and Their Use as Probes for Sensitive and Selective Detection of Mercury(II) Ions. Analytical Chemistry. 2012;84(12):53515357.

16. Liu R, Li H, Kong W, Liu J, Liu Y, Tong C, et al. Ultra-sensitive and selective $\mathrm{Hg}^{2+}$ detection based on fluorescent carbon dots. Materials Research Bulletin. 2013;48(7):2529-2534.

17. Wang L, Li B, Xu F, Shi X, Feng D, Wei D, et al. High-yield synthesis of strong photoluminescent $\mathrm{N}$-doped carbon nanodots derived from hydrosoluble chitosan for mercury ion sensing via smartphone APP. Biosensors and Bioelectronics. 2016;79:1-8.

18. Ganiga M, Cyriac J. Understanding the Photoluminescence Mechanism of Nitrogen-Doped Carbon Dots by Selective Interaction with Copper Ions. ChemPhysChem. 2016;17(15):23152321.

19. Sun X, Liu P, Wu L, Liu B. Graphene-quantum-dots-based ratiometric fluorescent probe for visual detection of copper ion. Analyst. 2015;140(19):6742-6747.

20. Jiang Y, Han Q, Jin C, Zhang J, Wang B. A fluorescence turn-off chemosensor based on $\mathrm{N}$-doped carbon quantum dots for detection of $\mathrm{Fe}^{3+}$ in aqueous solution. Materials Letters. 2015;141:366-368.

21. Xu Z, Wang C, Jiang K, Lin H, Huang Y, Zhang C. MicrowaveAssisted Rapid Synthesis of Amphibious Yellow Fluorescent Carbon Dots as a Colorimetric Nanosensor for Cr(VI). Particle \& Particle Systems Characterization. 2015;32(12):1058-1062.

22. Li X, Zhang S, Kulinich SA, Liu Y, Zeng H. Engineering surface states of carbon dots to achieve controllable luminescence for solid-luminescent composites and sensitive $\mathrm{Be}^{2+}$ detection. Scientific Reports. 2014;4:4976.

23. Shen J, Shang S, Chen X, Wang D, Cai Y. Facile synthesis of fluorescence carbon dots from sweet potato for $\mathrm{Fe}^{3+}$ sensing and cell imaging. Materials Science and Engineering: $C$. 2017;76:856-864.

24. Yadav I, Rathnam VSS, Yogalakshmi Y, Chakraborty S, Banerjee I, Anis A, et al. Synthesis and characterization of polyvinyl alcohol- carboxymethyl tamarind gum based composite films. Carbohydrate Polymers. 2017;165:159-168. 
25. Wang J, Ng YH, Lim YF, Ho GW. Vegetable-extracted carbon dots and their nanocomposites for enhanced photocatalytic $\mathrm{H} 2$ production. RSC Advances. 2014;4(83):44117-44123.

26. Zhuo Y, Miao H, Zhong D, Zhu S, Yang X. One-step synthesis of high quantum-yield and excitation-independent emission carbon dots for cell imaging. Materials Letters. 2015;139:197-200.

27. De B, Karak N. A green and facile approach for the synthesis of water soluble fluorescent carbon dots from banana juice. $R S C$ Advances. 2013;3(22):8286-8290.

28. Wang C, Xu Z, Cheng H, Lin H, Humphrey MG, Zhang C. A hydrothermal route to water-stable luminescent carbon dots as nanosensors for $\mathrm{pH}$ and temperature. Carbon. 2015;82:87-95.

29. Nie H, Li M, Li Q, Liang S, Tan Y, Sheng L, et al. Carbon Dots with Continuously Tunable Full-Color Emission and Their Application in Ratiometric pH Sensing. Chemistry of Materials. 2014;26:3104-3112.

30. Jia XF, Yang X, Li J, Li DY, Wang EK. Stable Cu nanoclusters: from an aggregation-induced emission mechanism to biosensing and catalytic applications. Chemical Communications. 2014;50(2):237239.

31. Kundu A, Nandi S, Das P, Nandi AK. Facile and green approach to prepare fluorescent carbon dots: Emergent nanomaterial for cell imaging and detection of vitamin $\mathrm{B}_{2}$. Journal of Colloid and Interface Science. 2016;468:276-283.Supplementary material

\section{Supplementary material}

The following online material is available for this article:

Scheme I. Synthesis procedure of C-dots by hydrothermal method employing acerola pulp fruit as carbon source.

Figure S1. UV-vis spectra of of C-dots solution obtained at different reaction times of hydrothermal treatment: (a) 6 , (b) 12, (c) 18 and (d) $24 \mathrm{~h}$. Temperature of hydrothermal treatment used was $160^{\circ} \mathrm{C}$.

Figure S2. Room temperature PL spectra of C-dots solution obtained at different reaction times of hydrothermal treatment: (a) 6, (b) 12, (c) 18 and (d) $24 \mathrm{~h}$. Temperature of hydrothermal treatment used was $160{ }^{\circ} \mathrm{C}$.

Figure S3. UV-vis spectra of of C-dots solution obtained at different temperatures of hydrothermal treatment. Reaction time of hydrothermal treatment used was $18 \mathrm{~h}$.

Figure S4. Digital photographic images of C-dots obtained at several reaction times: (a) 6, (b) 12, (c) 18 and (24) h. Temperature of hydrothermal treatment used was $160{ }^{\circ} \mathrm{C}$.

Figure S5. Composite films based on C-dots with PVA polymer (C-dots/PVA-2) (a) under visible and (b) UV lights.

Figure S6. C-dots/PVA-2 composite film in the absence and presence of $\mathrm{Fe}^{3+}$ ions: images have been taken under (A) visible light and (B) UV light. 